\title{
Pain and Nociception
}

\section{Mechanisms of Cancer-Induced Bone Pain}

Falk, Sarah; Dickenson, Anthony H

Published in:

Journal of Clinical Oncology

DOI:

$10.1200 / J C 0.2013 .51 .7219$

Publication date:

2014

Document version

Publisher's PDF, also known as Version of record

Document license:

CC BY

Citation for published version (APA):

Falk, S., \& Dickenson, A. H. (2014). Pain and Nociception: Mechanisms of Cancer-Induced Bone Pain. Journal of Clinical Oncology, 32(16), 1647-1654. https://doi.org/10.1200/JCO.2013.51.7219 
Sarah Falk, University of Copenhagen, Copenhagen, Denmark; and Anthony $\mathrm{H}$ Dickenson, University College London, London, United Kingdom.

Published online ahead of print at www.jco.org on May 5, 2014

Supported by the University of Copenhagen, Danish Cancer Society, and Direktør Jacob Madsen and Hustru Olga Madsens Fond (S.F.) and Wellcome Trust-funded London Pain Consortium (A.H.D.)

Authors' disclosures of potential conflicts of interest and author contributions are found at the end of this article.

Corresponding author: Anthony $\mathrm{H}$ Dickenson, BSc, PhD, Departments of Neuroscience, Physiology, and Pharmacology, University College London, Gower St, WC1E 6BT London, UK: e-mail: anthony.dickenson@ucl.ac.uk. (C) 2014 by American Society of Clinical Oncology

0732-183X/14/3216w-1647w/\$20.00 DOI: 10.1200/JCO.2013.51.7219

\section{Pain and Nociception: Mechanisms of Cancer-Induced Bone Pain}

Sarah Falk and Anthony H. Dickenson

$$
\begin{array}{llllllll}
\text { A } & \text { B } & \text { S } & \text { T } & \text { R } & \text { A } & \text { C } & \text { T }
\end{array}
$$

Cancer pain, especially pain caused by metastasis to bone, is a severe type of pain, and unless the cause and consequences can be resolved, the pain will become chronic. As detection and survival among patients with cancer have improved, pain has become an increasing challenge, because traditional therapies are often only partially effective. Until recently, knowledge of cancer pain mechanisms was poor compared with understanding of neuropathic and inflammatory pain states. We now view cancer-induced bone pain as a complex pain state involving components of both inflammatory and neuropathic pain but also exhibiting elements that seem unique to cancer pain. In addition, the pain state is often unpredictable, and the intensity of the pain is highly variable, making it difficult to manage. The establishment of translational animal models has started to reveal some of the molecular components involved in cancer pain. We present the essential pharmacologic and neurobiologic mechanisms involved in the generation and continuance of cancer-induced bone pain and discuss these in the context of understanding and treating patients. We discuss changes in peripheral signaling in the area of tumor growth, examine spinal cord mechanisms of sensitization, and finally address central processing. Our aim is to provide a mechanistic background for the sensory characteristics of cancer-induced bone pain as a basis for better understanding and treating this condition.

\section{J Clin Oncol 32:1647-1654. (C) 2014 by American Society of Clinical Oncology}

\section{INTRODUCTION}

Pain is a multifaceted sensation involving the entire nervous system. Pain processes usually start in the periphery, where tissue or nerve damage arises as a consequence of trauma, disease, or lesion, including the growth of a tumor within tissue or nerves. Different patterns of electrical and chemical events then transfer the painful messages via specialized nerves through to the spinal cord, where, after integration of the incoming messages, activity passes to many parts of the brain through a series of increasingly complex pathways. Each level is subject to enhancement and modulation. With simple acute pain, the peripheral and central processes are short-term, temporary changes that resolve when the tissue heals. By contrast, chronic pain is driven by longlasting, ongoing activity from the periphery that produces more persistent changes within spinal cord and brain circuits. In broad terms, pain can be divided into inflammatory pain (also called nociceptive pain), where the pain arises from chemical or natural stimuli from damaged tissue (surgery, osteoarthritis, or trauma), and neuropathic pain, caused by direct lesion or disease of the sensory nerves (diabetes or shingles). Here, the pain is predominantly initiated by changes in the ion channels that produce action potential within the nerves. Thus, inflammatory pain is initiated by chemical mediators, and neuropathic pain is initiated by altered electrical events (Fig 1). Table 1 lists the events that occur in these types of pain and compares them with cancer pain. Importantly, cancer-induced pain can involve both inflammatory and neuropathic mechanisms, because tumor expansion induces tissue damage and release of various inflammatory mediators. In addition, the cancer can also compress, grow within a sensory nerve, or denervate the target tissue, all causing neuropathic changes. Cancer pain can be considered a type of mixed pain, but increasing amounts of evidence suggest additional unique features indicating that it should be regarded as a separate pain state.

\section{CANCER PAIN}

As advances in treatment and detection of cancer have resulted in longer survival time, chronic pain has become an increasing problem, significantly compromising quality of life for many patients. ${ }^{10,11}$ Pain caused by metastasis to the bone is the most common source of moderate and severe cancer pain, and approximately $75 \%$ of patients with advanced cancer experience bone pain. ${ }^{12}$ Currently, 


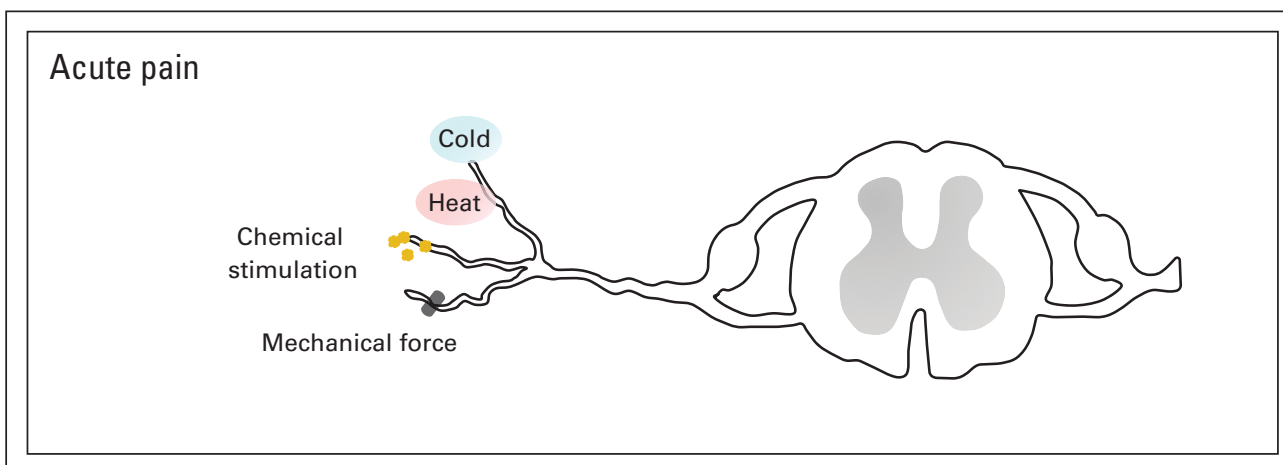

Inflammatory pain

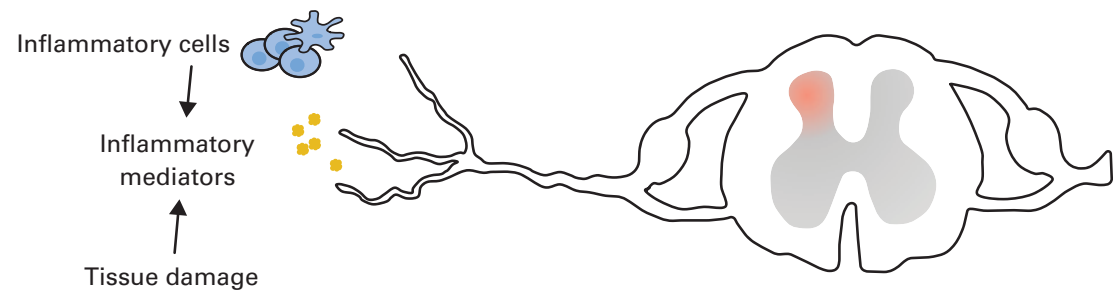

Peripheral sensitization

Central sensitization

Neuropathic pain

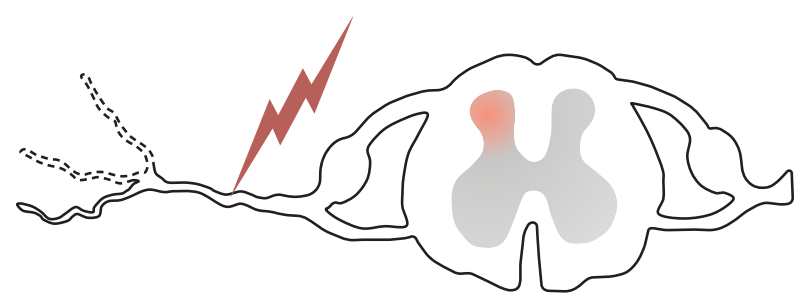

Loss or gain of function
Fig 1. Diagram of three main types of pain. only half experience temporary pain relief from conventional therapies, ${ }^{10}$ a clear indication of the need for development of new and better treatments.

Cancer-induced bone pain is a complex pain state involving a combination of background, spontaneous, and incident (movementevoked) pain. ${ }^{13,14}$ Background pain, a dull continuous pain, increases in intensity as the diseases progresses and can normally be treated fairly successfully with traditional analgesics. In contrast, spontaneous and incident pain, often referred to as breakthrough pain, are episodes of extreme pain breaking through the therapeutic regimen administrated to control background pain. ${ }^{15,16}$ Their intermittent nature makes these types of pain hard to treat, because the episodes tend to be rapid in onset and of short duration, making currently used analgesic therapies both insufficient and associated with dose-limiting adverse effects. $^{17,18}$

Cancer-induced bone pain is a mixed-mechanism pain state exhibiting elements of both neuropathic and inflammatory pain, but with distinctive modifications to the tissue and nerves in the periphery as well as unique neurochemical changes at the spinal cord level. Thus, it is a complex syndrome involving inflammatory, neuropathic, ischemic, and cancer-specific mechanisms, often occurring at more than one site (Table 1). Inflammatory infiltration occurs as a result of direct tissue damage caused by tumor growth as well as release of pain mediators by the cancer cells. The neuropathic component of the pain can result from cancer-induced damage to the sensory nerves caused by infiltration and/or compression by the tumor cells, tumor-induced hyperinnervation, ${ }^{19}$ and stretching or denervation as the bone expands and degrades. In addition, neuropathy can arise as a subsequent consequence of therapeutic intervention, such as chemotherapy or surgery. The mechanisms behind the pathophysiology are both peripherally and centrally induced, with altered impulses from the bone and surrounding tissues, resulting in a state of general hyperexcitability of the neurons in the dorsal horn of the spinal cord. Interestingly, the presence and intensity of the pain are not necessarily correlated with the size or number of active malignancies; whereas some metastatic sites are completely painless, others cause patients to experience severe pain from a single bone metastasis, even in the absence of fracture. ${ }^{16}$ This is likely the result of different balances between peripheral and central mechanisms and the ability of central modulatory systems to reduce peripheral activity, both of which could vary among patients. The unique neurochemical signature of cancer-induced bone pain may explain the reduced efficacy of traditional analgesics, suggesting that polypharmacy or alternative approaches may be better options for effective pain management. 


\begin{tabular}{|c|c|}
\hline Type of Pain & Mechanism \\
\hline Acute $^{1,2}$ & $\begin{array}{l}\text { Activation of nociceptors by mechanical and therma } \\
\text { stimuli } \\
\text { No long-term tissue or nerve damage } \\
\text { Normal healing } \\
\text { Normal transmission to spinal cord and brain } \\
\text { Activation of sensory areas of brain }\end{array}$ \\
\hline Neuropathic ${ }^{3,4}$ & $\begin{array}{l}\text { Damage or lesion to sensory fibers or neurons } \\
\text { Denervation of spinal cord from periphery } \\
\text { Altered ion channel function } \\
\text { Gain and loss of somatosensory function } \\
\text { Increased compensatory spinal transmitter release } \\
\text { Induction of central sensitization and windup } \\
\text { Increased transmission to sensory and affective } \\
\text { brain areas } \\
\text { Loss of descending inhibition; gain of facilitation } \\
\text { Ongoing and evoked pain } \\
\text { Comorbidities }\end{array}$ \\
\hline Inflammatory ${ }^{4-6}$ & $\begin{array}{l}\text { Chemical activation of nociceptors by mediators } \\
\text { Mediators produced by damaged tissue and } \\
\text { immune cells } \\
\text { Increased levels of cytokines and growth factors } \\
\text { Altered vascular events } \\
\text { Gain of somatosensory function } \\
\text { Peripheral sensitization } \\
\text { Enhanced inputs into spinal cord } \\
\text { Induction of central sensitization and windup } \\
\text { Increased transmission to sensory and affective } \\
\text { brain areas } \\
\text { Changes in descending inhibition; gain of facilitation } \\
\text { Ongoing and evoked pain } \\
\text { Comorbidities }\end{array}$ \\
\hline Cancer $r^{7-9}$ & $\begin{array}{l}\text { Chemical activation of nociceptors by mediators } \\
\text { Mediators produced by damaged tissue and } \\
\text { immune cells } \\
\text { Increased levels of cytokines and growth factors } \\
\text { Increased innervation of tissue } \\
\text { Breakdown of bone } \\
\text { Altered vascular events } \\
\text { Gain of somatosensory function } \\
\text { Peripheral sensitization } \\
\text { Distention and denervation of sensory fibers or } \\
\text { neurons } \\
\text { Compression and invasion of nerves by tumor cells } \\
\text { Altered ion channel function } \\
\text { Enhanced inputs into spinal cord } \\
\text { Induction of central sensitization and windup } \\
\text { Increased transmission to sensory and affective } \\
\text { brain areas } \\
\text { Gain of descending facilitation } \\
\text { Ongoing and evoked pain } \\
\text { Comorbidities }\end{array}$ \\
\hline
\end{tabular}

\section{ANIMAL MODELS}

To meet the clinical need for better therapies, in vivo models accurately mimicking the human condition have been developed. The pivotal problem lies in identifying the role of molecules in the processing of pain, in the context of the whole animal. Therefore, to achieve these aims, in vivo models (ie, integrated systems) are essential to study pain, because the interactions among peripheral activity, spinal transmission, modulatory systems, and finally brain systems determine the net overall activity that leads to the final pain sensation. What is currently known about cancer pain is based on detailed exploration of the changes that occur to tissue, nerves, and surrounding structures when tumor cells grow within a bone. Previously, animal models of metastatic cancer were based on systemic injection of carcinoma cells, resulting in animals in poor health, unpredictable locations of multiple bone metastases, and wide variability among animals. ${ }^{20,21}$ More recently, the pain state has been modeled by direct injection of cancer cells into the intramedullary space of long bones, resulting in translational models with site-specific metastases and characteristics reflecting the clinical condition, with progressive tumor-induced bone destruction, elevated osteoclast activity, and progressive and distinctive nocifensive behavior. ${ }^{22}$ These models have enabled systematic investigation of the molecular mechanisms involved and revealed correlation of tumor growth and the surrounding microenvironment of the tumor with bone destruction, site-specific nocifensive behavior, and neurobiologic changes in the periphery and at the levels of the spinal cord and brain.

Since the first model involving direct injection of sarcoma cells into the femurs of mice was described in 1999, models have been modified and refined using different species, bones, and cancer lines. ${ }^{22}$ Injection of tumor cells into different bones (femur, calcaneus, humerus, and tibia ${ }^{23-28}$ ) result in pain conditions that seem similar in nature and in which sex has only a minor effect on progression of the pain state. ${ }^{29}$ In contrast, different types of cell lines cause distinct types of behavior, bone destruction, and neurochemical reorganizations in the spinal cord, demonstrating that multiple mechanisms are involved in the generation and continuance of cancer-induced bone pain. ${ }^{25}$

\section{PERIPHERAL MECHANISMS}

The biology of cancer-induced bone pain involves a complex interplay among the tumor cells, peripheral nerves, and cells of the bone (Fig 2). Bone marrow, mineralized bone, and periosteum are highly innervated by nerve fibers, ${ }^{30-33}$ and as the cancer cells invade the bone and start proliferating, mechanical damage, distension, and entrapment of the primary afferent fibers lead to a neuropathic state. Additionally, numerous nociceptive and inflammatory responses are triggered, subsequently recruiting inflammatory cells such as macrophages, neutrophils, and T cells, ${ }^{34}$ which release a plethora of stimuli acting on the primary afferent fibers, bone cells, and cancer cells and initiate a cascade of mechanisms, including activation and sensibilization of nociceptors, degradation of bone, and tumor growth. ${ }^{34-38}$

As the disease advances, the cancer cells induce damage and deformation of the peripheral nerves in the bone. The bone is innervated by a tight network of both sympathetic and sensory neurons, and although the periosteum has long been considered the most densely innervated part of the bone, when total volume is considered, the greatest number of nerve fibers are found in the bone marrow, followed by the mineralized part of the bone and finally the periosteum. ${ }^{32,39,40}$ Innervation of the bone by various nerve fibers has been established, and the size, neurochemistry, and segmental distribution of the neuronal projection from the bone to the dorsal root ganglions (DRGs) and dorsal horn have been demonstrated as consistent with having functional roles in nociception. ${ }^{41}$ Confinement of NCTC (National Collection of Type Cultures) clone 2472 osteolytic tumor cells 


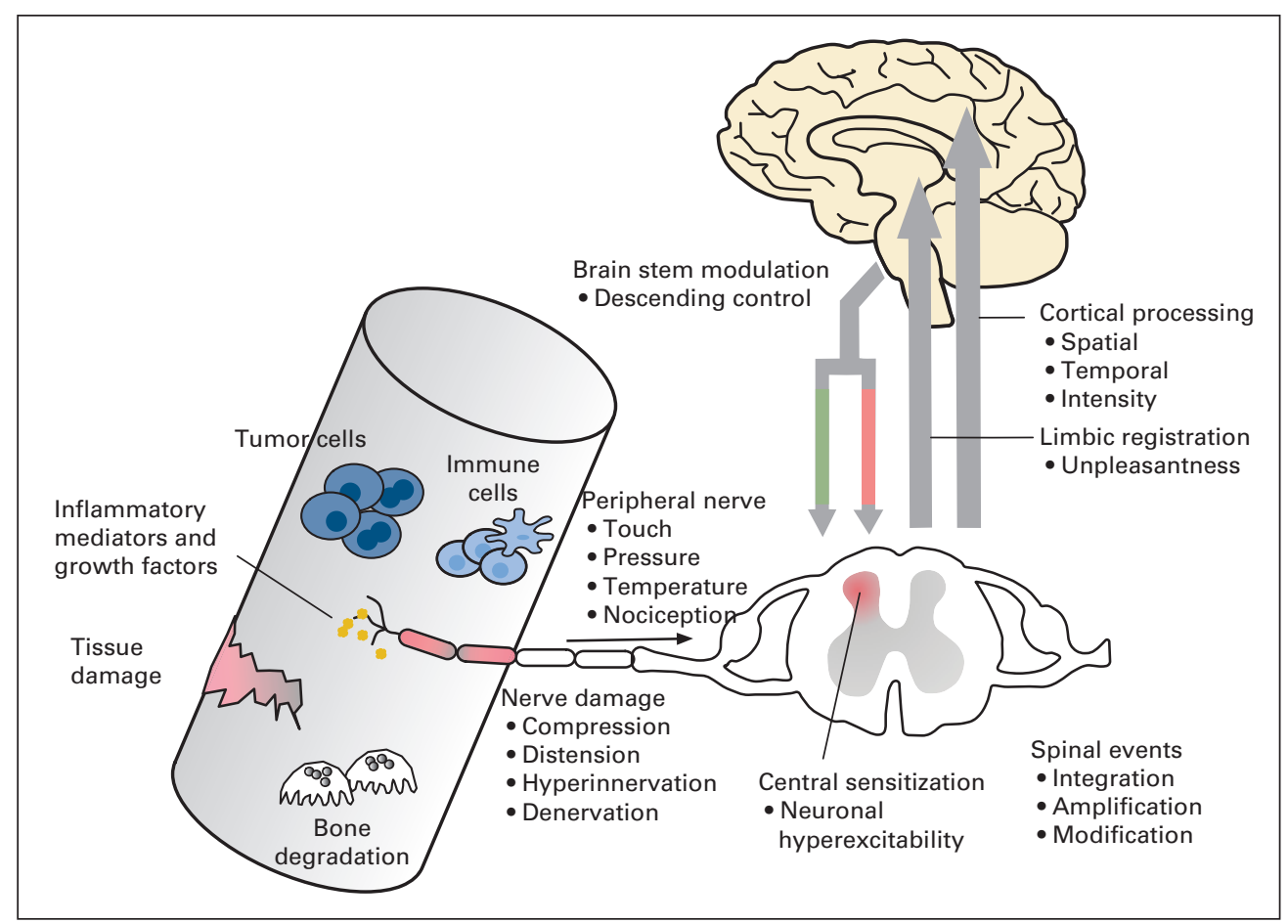

Fig 2. Basic mechanisms of pain processes at peripheral, spinal, and supraspinal sites and influences of various peripheral mechanisms, including tumor cell- and immune cell-mediated release of pronociceptive factors, direct tissue damage, and bone degradation through osteoclast activation. Because of peripheral events, central excitability changes are recruited. Combination of these events produces final pain experience at highest centers of brain.

in mouse femur causes injury to both the myelinated and unmyelinated sensory nerve fibers innervating the bone and marrow, ${ }^{42}$ and recently, studies have shown that cancer cells in the bone induce sprouting and reorganization of sensory and sympathetic fibers in the periosteum. ${ }^{43}$ The highly disorganized sprouting causes a general increase in nerve fiber density of both sensory and sympathetic nerve fibers and formations of neuroma-like structures, similar to those observed in conditions known to produce spontaneous ectopic pain episodes, such as complex regional pain syndrome. Therefore, it has been speculated that the neuroma-like structures caused by cancer cells in the bone contribute to episodes of breakthrough pain or even movement-induced pain. ${ }^{19,44}$ These mechanisms might be linked not only to changes in morphology but also to the reorganization of sensory and sympathetic fibers. In normal healthy bone, sensory and sympathetic fibers are separated; however, tumor-induced sprouting causes an intermingling of the two fiber types, allowing sympathetic fibers to potentially trigger nociceptive stimuli, exciting the nearby sensory fibers. ${ }^{19}$ In addition, the sprouting and neuroma formation are likely associated with the expression and release of nerve growth factors (NGFs) by the tumor cells and tumor-associated cells. Therapeutic treatment with NGF-specific antibodies blocks sprouting and attenuates pain without affecting tumor growth or bone destruction, suggesting an important role for NGFs in driving bone cancer pain. ${ }^{43}$ This important evidence suggests that potential clinical interventions could target NGFs, and indeed, tanezumab, despite some concerns about adverse effects, has been shown to be effective in patients with osteoarthritis and lower back pain ${ }^{45,46}$ and has potential for the treatment and palliation of cancer pain.

In addition to direct nerve damage, cancer cells compromise the mechanical strength of the bone. Under physiologic conditions, normal bone remodeling is balanced by formation of bone by osteoblasts and resorption of bone by osteoclasts. ${ }^{47}$ Depending on the type of cancer cells involved, either osteolytic (net resorption) or osteoblastic (net deposition) bone lesions can occur, both compromising microarchitecture and strength. ${ }^{48,49}$ In most metastatic cancers, net resorption of the bone occurs, resulting in bone less resistant to bending and with increased risk of facture. Osteolytic lesions are caused by proliferation and hypertrophy of osteoclasts, which in turn induce bone remodeling by releasing various acidic and lytic enzymes, causing both degradation of bone and a decrease in the $\mathrm{pH}$ of the local environment surrounding the tumor. ${ }^{47,49}$ It has been suggested that local acidosis, caused by production of extracellular protons, may also be involved in sensitizing the primary afferents through activation of acid-sensitive ion channels on the primary afferents in the bone ${ }^{50}$ (Fig 2).

The increased osteoclast proliferation and activation observed in cancer-induced bone pain are connected to an increased production and release of RANK ligand (RANK-L). RANK-L is normally expressed on various cell types, including osteoblasts, and is, in combination with colony-stimulating factor-1 (CSF-1), essential for normal proliferation and activation of osteoclasts through activation of the RANK receptor expressed on osteoclast precursors. ${ }^{51,52}$ Interaction between RANK-L and the RANK receptor is normally controlled by osteoprotegrin (OPG), released by osteoblasts, which acts as a decoy receptor for RANK-L and prevents its binding, thus inhibiting osteoclast activation. The tumor interrupts the normal balance between RANK and RANK-L by increasing secretion of RANK-L from both cancer cells and $\mathrm{T}$ cells, ${ }^{52,53}$ thus accelerating bone degradation. After injection of OPG into mice with early-stage disease, tumor burden was unaffected, but a dramatic decrease in number of osteoclasts and bone destruction ensued. In addition, there was a significant decrease in nocifensive behavior, and neurochemical changes normally introduced in the spinal cord by cancer-induced bone pain were reversed. ${ }^{48}$ Various OPG-like peptidominetics and anti-RANK-L antibodies, such as denosumad, have been tested in clinical trials, demonstrating 
suppression of bone resorption in patients with different bone degenerative diseases, including cancer-induced bone diseases. ${ }^{54,55}$ Similarly, bisphosphonates have been demonstrated to suppress bone degradation and pain behavior in both animal models and in the clinic. ${ }^{56}$ In both cases, pain relief is not directly related to inhibition of nociception; rather, it is a more indirect effect caused by a decrease in the osteolytic effect of the tumor.

The inflammatory infiltration associated with tumor growth initiates a release of various growth factors, cytokines, interleukins, chemokines, prostanoids, endothelins, and other mediators speculated to contribute to the development and/or maintenance of pain $^{34-38,57,58}$ (Fig 2). Although the inflammatory component is likely only a partial contributor to the overall pain state, various nonsteroidal anti-inflammatory drugs (NSAIDs) are commonly used in the clinic as supplements to stronger analgesics so patients can benefit from potential additive effects. ${ }^{59}$ NSAIDs produce analgesia through inhibition of the cyclooxygenase (COX) pathway, thereby reducing production of prostaglandins, and cancer cells and macrophages associated with bone tumors express high levels of COX-2. ${ }^{60,61}$ However, preclinical evidence seems conflicting. Some studies have shown that selective COX-1 and COX-2 inhibitors have only little effect on pain-related behavior in some animal models of cancer-induced bone pain, ${ }^{24,59}$ whereas others have demonstrated that both acute and chronic administration of other COX-2 inhibitors reduce ongoing as well as movement-evoked pain, in addition to effectively reducing tumor burden and level of bone destruction. ${ }^{62-64}$ The differences may be accounted for by the fact that different COX inhibitors and different protocols of administration were employed in the studies. However, there is still a general lack of clinical evidence to support a significant analgesic effect of NSAIDs in cancer-induced bone pain. ${ }^{52,59}$

Other factors related to tissue damage and inflammation have been studied to provide new therapeutic targets. Currently, purinergic receptors, especially ATP receptors, have received much attention in relation to chronic pain. ${ }^{65}$ ATP is found in all cells, so any tissue or nerve damage is likely to release this mediator. Purinergic receptors are divided into $\mathrm{P} 2 \mathrm{X}$ receptors, ligand-gated ion channels, and $\mathrm{P} 2 \mathrm{Y}$ receptors acting through $\mathrm{G}$ protein-coupled mechanisms. The P2X3 receptor has been studied intensively in relation to pain; these receptors are expressed selectively on small-diameter nociceptive fibers, whereas many other purinergic receptors are diversely expressed in many different tissues throughout the body. ${ }^{65}$ Electrophysiologic studies in rats with cancer-induced bone pain have demonstrated that both systemic and spinal applications of a P2X3 and P2X2/3 antagonist, AF-353, inhibit neuronal responses to electrical, mechanical, and thermal stimulations as well as attenuate pain behavior. ${ }^{66}$ In addition, studies using a different P2X3 and P2X2/3 antagonist have also shown a reduction in pain behavior in both murine and rat models of cancerinduced bone pain. ${ }^{67-69}$ These receptors have the potential to be novel targets for analgesia.

Damage to the peripheral nerves and degradation of the bone, in addition to tumor-related release of inflammatory mediators, can cause sensitization of the nociceptors and/or neuropathy in the periphery, both significantly increasing the primary afferent drive to the spinal cord. Because a major action of a number of drugs, including opioids, is to counter these inputs as they enter the spinal cord, these increased afferent messages may explain some of the difficulties in controlling cancer pain.

\section{CENTRAL MECHANISMS}

There are unique neurochemical changes in the DRGs and dorsal horn during cancer-induced pain, ${ }^{22,48}$ suggesting that peripheral changes drive central spinal hypersensitive states of neurons projecting to the parts of the brain involved in pain sensation (Fig 2). Changes in neurons and glia cells in the dorsal horn indicate separate but overlapping mechanisms with other chronic pain states. Whereas inflammatory and neuropathic pain induce changes in substance $\mathrm{P}$ and calcitonin gene-related peptide (CGRP) levels in the dorsal horn and DRGs, these changes are absent in cancer-induced bone pain. ${ }^{48}$ Instead, increased expression of c-FOS and dynorphin are seen, especially in the deeper laminae of the dorsal horn, accompanied by massive spinal astrocyte hypertrophy and upregulation of activating transcription factor 3 (ATF3) and galanin, markers of nerve damage, in DRGs. ${ }^{42,48}$ The neurochemical changes correlate with tumor growth and subsequent damage of the surrounding bone. However, the finding that multiple metastases are not necessarily more painful than single metastasis can be explained by the ability of the CNS to dampen or modulate pain messages at central levels. Changes in dynorphin and c-FOS expression have also been observed in inflammatory and neuropathic pain models, suggesting similar components contribute to parts of the cancer pain state. ${ }^{70,71}$

Spinal cord neurons in models of cancer-induced bone pain show enhanced responses to evoked stimuli, reflecting a general hyperexcitability of the neurons, as has also been seen in inflammatory and neuropathic states. ${ }^{72,73}$ In addition, there is an increase in the receptive field for neurons in the superficial dorsal horn and alteration in the ratio between nociceptive-specific neurons and wide dynamic range (WDR) neurons, features of central sensitization. Animals with cancer-induced bone pain display an increased number of WDR neurons in the superficial dorsal horn, resulting in an increased probability of response to low-threshold peripheral inputs; in contrast, WDR neurons in the deeper dorsal horn display less pronounced changes, although responses to thermal and electrical stimuli are significantly increased. ${ }^{74}$ Even in animals chronically treated with morphine, the abnormally high ratio of WDR cells persists, suggesting that there remains greater access to low-threshold stimuli, which may be related to the problem of controlling allodynia and breakthrough pain in the clinic. ${ }^{75}$ Neurobiologic reorganization such as this seems unique to cancer-induced bone pain and is not seen in inflammatory or neuropathic models. Furthermore, chronic treatment with gabapentin, which modulates calcium channels at the spinal level and so reduces transmitter release from afferents, temporarily attenuates plasticity by shifting the abnormally high WDR-like population back to nociceptive-specific-like cells and reducing the input of and C-fiber response to electrical stimuli. ${ }^{74}$ Together this suggests that the phenotypical shift in superficial dorsal horn neurons from nociceptive-specific neurons to WDR-like neurons is linked to alterations in synapses from the periphery to the spinal cord as well as in intrinsic signaling. On the basis of this preclinical evidence, drugs such as gabapentin might be useful agents.

In addition, spinal neurons show increased excitability; here, an important factor is the N-methyl-D-aspartate (NMDA) receptor for glutamate, the major excitatory transmitter in the nervous system, found in almost all pain fibers. Activation of the NMDA receptor leads 
to windup, where a constant stimulus elicits responses increased fourto five-fold, although peripheral input remains the same. Thus, windup is a plausible basis for what has been termed central sensitization. Spinal neurons that become hyperexcitable show reduced thresholds, increased receptive field sizes, and ongoing stimulusindependent activity as well as greater evoked responses. This activity is a likely basis for the allodynias, hyperalgesia, and spontaneous pain seen in patients, because many of these spinal neurons project to higher centers of the brain. Ketamine blocks the NMDA receptor complex, and use of NMDA antagonists has been a useful tool for demonstration of NMDA receptor-mediated hypersensitivity in patients with pain resulting from surgery, tissue damage, neuropathy, and fibromyalgia. ${ }^{76} \mathrm{Re}-$ cently, involvement of the NR2B receptor in behavioral consequences of bone cancer pain has been demonstrated, ${ }^{77}$ and we have studied the ability of antagonists at the NR2B receptor as well as ketamine to reduce the altered neuronal responses provoked by bone cancer pain (Patel and Dickenson, unpublished data).

Clinically, opioids remain the most effective pharmacologic treatment for severe pain resulting from malignancy in the bone. Opioids have a number of mechanisms related to analgesia, but a major site is the spinal cord, where opioids reduce both painful inputs and inhibit spinal neuronal activity. ${ }^{76}$ However, adverse effects associated with the high doses required to significantly reduce episodes of incident pain make opioid therapy far from perfect. Pharmacologic studies have shown that the analgesic effects of opioids can be less effective in cancer-induced bone pain compared with other pain states. ${ }^{78-80}$ Treatment with morphine reduces pain behavior in animals with cancer-induced bone pain, although only in early-stage disease involving mild to moderate pain intensity; as the severity increases, the effectiveness of morphine is reduced, and the analgesic effects are only observed with doses that also cause substantial adverse effects. $^{81,82}$

\section{SUPRASPINAL MECHANISMS}

After integration and modulation at the spinal level, the enhanced pain messages are sent to the brain, where the final individual pain experience is generated (Fig 2). Activity in both the sensory discriminatory parts of the brain and the affective and emotional brain areas will change in different pain states. The sensory aspects of pain are established by activity in cortical areas through relays in the thalamus. The equally important emotional or affective components of pain are likely to be through inputs from spinal neurons to areas such as the amygdala. Persistent inputs into the limbic brain areas, including the amygdala, are likely to be causal regarding comorbidities that patients often report resulting from ongoing pain that disrupt normal functioning and generate fear, depression, and sleep problems. Finally, pain alters function and activity in the descending controls, which relay information from higher brain centers via the midbrain and brainstem to the spinal cord. Thus, a reciprocal relationship exists, whereby mood, anxiety, and so on can influence pain. These descending controls link the higher parts of the brain back to the spinal cord and are controlled by areas such as the amygdala. ${ }^{83}$ Descending pathways run from the central gray to brainstem nuclei, where the final projections to the spinal cord originate. Cells in these areas allow the brain to generate descending excitation or inhibition. The balance in acute pain states shifts in pathophysiologic pain models so that exci- tation dominates. Thus, loss of inhibition or gain of facilitation promotes pain, whereas evoking inhibition reduces pain. Preclinical studies have suggested that the bases for this are descending noradrenergic, mostly inhibitory, and certain serotonergic controls that facilitate pain. These monoamine descending controls regulate spinal neuronal activity bidirectionally and underlie the efficacy of antidepressants for the treatment of pain. ${ }^{84}$ Little has been done regarding descending controls in cancer pain models, but blocking the 5HT3 receptor attenuates descending excitatory controls from the brain to the spinal cord and reduces the response of superficial dorsal horn WDR-like cells to thermal and mechanical stimuli. ${ }^{73}$ This strongly suggests that part of the increased spinal excitability seen in the cancerinduced bone pain model is not simply peripheral or spinal but that abnormal descending controls contribute to the changes. These alterations would suggest that central changes are important, and of course, these may be partly driven by limbic changes, themselves subserving comorbidities common in patients, such as fear, sleep problems, and depression.

Thus, a series of molecular and neurobiologic changes occur in models of cancer-induced bone pain. These overlap with changes that have been observed in states of inflammatory pain and pain after neuropathy. These pathologic events start in the periphery and continue into the spinal cord and brain, where finally, there are altered descending controls back to the spinal cord. However, additional changes ensue so that cancer-induced bone pain has unique characteristics. Taken as a whole, these series of altered processes can explain the ongoing pain, altered sensory perceptions, such as allodynias and hyperalgesias, and comorbidities so common in patients. This complexity may seem daunting and is a basis for the issues seen in the clinic in terms of treating pain. However, this same complexity and mix of inflammatory and neuropathic components offer treatment opportunities, where drugs with actions in different indications may be efficacious. Finally, the existence of multiple mechanisms provides a rational basis for the use of combination therapy in cases where a single agent is not enough.

\section{AUTHORS' DISCLOSURES OF POTENTIAL CONFLICTS OF INTEREST}

Although all authors completed the disclosure declaration, the following author(s) and/or an author's immediate family member(s) indicated a financial or other interest that is relevant to the subject matter under consideration in this article. Certain relationships marked with a " $U$ " are those for which no compensation was received; those relationships marked with a "C" were compensated. For a detailed description of the disclosure categories, or for more information about ASCO's conflict of interest policy, please refer to the Author Disclosure Declaration and the Disclosures of Potential Conflicts of Interest section in Information for Contributors. Employment or Leadership Position: None Consultant or Advisory Role: Anthony H. Dickenson, Grünenthal (C), Pfizer (C) Stock Ownership: None Honoraria: Anthony H. Dickenson, Grünenthal, Pfizer, ProStrakan Research Funding: None Expert Testimony: None Patents: None Other Remuneration: None

\section{AUTHOR CONTRIBUTIONS}

Conception and design: All authors

Manuscript writing: All authors

Final approval of manuscript: All authors 


\section{REFERENGES}

1. Loeser JD, Melzack R. Pain: An overview. Lancet 353:1607-1609, 1999

2. Tracey I, Mantyh PW: The cerebral signature for pain perception and its modulation. Neuron 55: 377-391, 2007

3. Dickenson AH, Matthews EA, Suzuki R: Neurobiology of neuropathic pain: Mode of action of anticonvulsants. Eur J Pain 6:51-60, 2002 (suppl A)

4. Harvey VL, Dickenson AH: Mechanisms of pain in nonmalignant disease. Curr Opin Support Palliat Care 2:133-139, 2008

5. Schaible HG: Mechanisms of chronic pain in osteoarthritis. Curr Rheumatol Rep 14:549-556, 2012

6. Basbaum Al, Bautista DM, Scherrer G, et al: Cellular and molecular mechanisms of pain. Cell 139:267-284, 2009

7. Sabino MA, Mantyh PW: Pathophysiology of bone cancer pain. J Support Oncol 3:15-24, 2005

8. Mantyh PW: Central pain, in Koltzenburg M, McMahon SB (eds): Wall and Melzack's Textbook of Pain (ed 5). Philadelphia, PA, Elsevier, 2006, pp 1087-1098

9. Gordon-Williams R, Dickenson T: Pathophysiology of pain in cancer and other terminal diseases, in Hanks G, Cherny NI, Christakis NA, et al (eds): Oxford Textbook of Palliative Medicine (ed 4). New York, NY, Oxford University Press, 2011, pp 587-599

10. Meuser T, Pietruck $C$, Radbruch $L$, et al: Symptoms during cancer pain treatment following WHO-guidelines: A longitudinal follow-up study of symptom prevalence, severity and etiology. Pain 93:247-257, 2001

11. Portenoy RK, Lesage P: Management of cancer pain. Lancet 353:1695-1700, 1999

12. Foley KM: Treatment of cancer-related pain. J Natl Cancer Inst Monogr 32:103-104, 2004

13. Portenoy RK, Hagen NA: Breakthrough pain: Definition, prevalence and characteristics. Pain 41: 273-281, 1990

14. Mercadante S, Arcuri E: Breakthrough pain in cancer patients: Pathophysiology and treatment. Cancer Treat Rev 24:425-432, 1998

15. Portenoy RK, Payne D, Jacobsen P: Breakthrough pain: Characteristics and impact in patients with cancer pain. Pain 81:129-134, 1999

16. Mercadante S: Malignant bone pain: Pathophysiology and treatment. Pain 69:1-18, 1997

17. Mercadante S, Maddaloni S, Roccella S, et al: Predictive factors in advanced cancer pain treated only by analgesics. Pain 50:151-155, 1992

18. Bruera $E$, Schoeller T, Wenk R, et al: A prospective multicenter assessment of the Edmonton staging system for cancer pain. J Pain Symptom Manage 10:348-355, 1995

19. Mantyh WG, Jimenez-Andrade JM, Stake JI, et al: Blockade of nerve sprouting and neuroma formation markedly attenuates the development of late stage cancer pain. Neuroscience 171:588-598, 2010

20. Kostenuik PJ, Orr FW, Suyama K, et al: Increased growth rate and tumor burden of spontaneously metastatic Walker 256 cancer cells in the skeleton of bisphosphonate-treated rats. Cancer Res 53:5452-5457, 1993

21. Sasaki A, Yoneda T, Terakado N, et al: Experimental bone metastasis model of the oral and maxillofacial region. Anticancer Res 18:1579-1584, 1998

22. Schwei MJ, Honore $P$, Rogers $S D$, et al: Neurochemical and cellular reorganization of the spinal cord in a murine model of bone cancer pain. J Neurosci 19:10886-10897, 1999

23. Pacharinsak C, Beitz $A$ : Animal models of cancer pain. Comp Med 58:220-233, 2008

24. Medhurst SJ, Walker K, Bowes M, et al: A rat model of bone cancer pain. Pain 96:129-140, 2002

25. Sabino MA, Luger NM, Mach DB, et al: Different tumors in bone each give rise to a distinct pattern of skeletal destruction, bone cancer-related pain behaviors and neurochemical changes in the central nervous system. Int J Cancer 104:550-558, 2003

26. Wacnik PW, Eikmeier LJ, Ruggles $T R$, et al: Functional interactions between tumor and peripheral nerve: Morphology, algogen identification, and behavioral characterization of a new murine model of cancer pain. J Neurosci 21:9355-9366, 2001

27. Wacnik PW, Kehl LJ, Trempe TM, et al: Tumor implantation in mouse humerus evokes movementrelated hyperalgesia exceeding that evoked by intramuscular carrageenan. Pain 101:175-186, 2003

28. Menéndez L, Lastra A, Fresno MF, et al: Initial thermal heat hypoalgesia and delayed hyperalgesia in a murine model of bone cancer pain. Brain Res 969:102-109, 2003

29. Falk S, Uldall M, Appel C, et al: Influence of sex differences on the progression of cancerinduced bone pain. Anticancer Res 33:1963-1969, 2013

30. Calvo W, Forteza-Vila J: On the development of bone marrow innervation in new-born rats as studied with silver impregnation and electron microscopy. Am J Anat 126:355-371, 1969

31. Hara-Irie F, Amizuka N, Ozawa H: Immunohistochemical and ultrastructural localization of CGRPpositive nerve fibers at the epiphyseal trabecules facing the growth plate of rat femurs. Bone 18:2939, 1996

32. Mach DB, Rogers SD, Sabino MC, et al: Origins of skeletal pain: Sensory and sympathetic innervation of the mouse femur. Neuroscience 113: 155-166, 2002

33. Thurston TJ: Distribution of nerves in long bones as shown by silver impregnation. J Anat 134:719-728, 1982

34. Mantyh PW, Clohisy DR, Koltzenburg M, et al: Molecular mechanisms of cancer pain. Nat Rev Cancer 2:201-209, 2002

35. Apfel SC: Neurotrophic factors and pain. Clin J Pain 16:S7-S11, 2000

36. Dray A: Inflammatory mediators of pain. $\mathrm{Br} \mathrm{J}$ Anaesth 75:125-131, 1995

37. Funk CD: Prostaglandins and leukotrienes: Advances in eicosanoid biology. Science 294:18711875, 2001

38. Ueno A, Oh-ishi S: Critical roles for bradykinin and prostanoids in acute inflammatory reactions: $\mathrm{A}$ search using experimental animal models. Curr Drug Targets Inflamm Allergy 1:363-376, 2002

39. Serre CM, Farlay D, Delmas PD, et al: Evidence for a dense and intimate innervation of the bone tissue, including glutamate-containing fibers. Bone 25:623-629, 1999

40. Jimenez-Andrade JM, Mantyh WG, Bloom $A P$, et al: A phenotypically restricted set of primary afferent nerve fibers innervate the bone versus skin: Therapeutic opportunity for treating skeletal pain. Bone 46:306-313, 2010

41. Ivanusic JJ: Size, neurochemistry, and segmental distribution of sensory neurons innervating the rat tibia. J Comp Neurol 517:276-283, 2009

42. Peters CM, Ghilardi JR, Keyser CP, et al: Tumor-induced injury of primary afferent sensory nerve fibers in bone cancer pain. Exp Neurol 193: 85-100, 2005

43. Jimenez-Andrade JM, Ghilardi JR, CastañedaCorral G, et al: Preventive or late administration of anti-NGF therapy attenuates tumor-induced nerve sprouting, neuroma formation, and cancer pain. Pain 152:2564-2574, 2011

44. Jänig W, Baron R: Complex regional pain syndrome: Mystery explained? Lancet Neurol 2:687697, 2003

45. Spierings EL, Fidelholtz J, Wolfram G, et al: A phase III placebo- and oxycodone-controlled study of tanezumab in adults with osteoarthritis pain of the hip or knee. Pain 154:1603-1612, 2013

46. Hill R: Blocking the effects of NGF as a route to safe and effective pain relief: Fact or fancy? Pain 152:2200-2201, 2011

47. Blair HC: How the osteoclast degrades bone. Bioessays 20:837-846, 1998

48. Honoré P, Schwei J, Rogers SD, et al: Cellular and neurochemical remodeling of the spinal cord in bone cancer pain. Prog Brain Res 129:389-397, 2000

49. Halvorson KG, Sevcik MA, Ghilardi JR, et al: Similarities and differences in tumor growth, skeletal remodeling and pain in an osteolytic and osteoblastic model of bone cancer. Clin J Pain 22:587-600, 2006

50. Julius $D$, Basbaum Al: Molecular mechanisms of nociception. Nature 413:203-210, 2001

51. Colvin L, Fallon M: Challenges in cancer pain management: Bone pain. Eur J Cancer 44:10831090, 2008

52. Urch C: The pathophysiology of cancerinduced bone pain: Current understanding. Palliat Med 18:267-274, 2004

53. Clohisy DR, Perkins SL, Ramnaraine ML: Review of cellular mechanisms of tumor osteolysis. Clin Orthop Relat Res 373:104-114, 2000

54. Schwarz EM, Ritchlin CT: Clinical development of anti-RANKL therapy. Arthritis Res Ther 9:S7, 2007 (suppl 1)

55. Lipton A, Goessl C: Clinical development of anti-RANKL therapies for treatment and prevention of bone metastasis. Bone 48:96-99, 2011

56. Drake MT, Clarke BL, Khosla S: Bisphosphonates: Mechanism of action and role in clinical practice. Mayo Clin Proc 83:1032-1045, 2008

57. Safieh-Garabedian B, Poole S, Allchorne A, et al: Contribution of interleukin-1 beta to the inflammationinduced increase in nerve growth factor levels and inflammatory hyperalgesia. Br J Pharmacol 115:12651275, 1995

58. Sorkin LS, Xiao WH, Wagner R, et al: Tumour necrosis factor-alpha induces ectopic activity in nociceptive primary afferent fibres. Neuroscience 81 : 255-262, 1997

59. Patel S, Dickenson AH: Mechanisms of cancer pain: Experimental data, in Mogel J (ed): Pain 2010: An Updated Review—Refresher Course Syllabus. Washington, DC, IASP Press, 2010, pp 27-35

60. Vasko MR: Prostaglandin-induced neuropeptide release from spinal cord. Prog Brain Res 104: 367-380, 1995

61. Chen EP, Smyth EM: COX-2 and PGE2dependent immunomodulation in breast cancer. Prostaglandins Other Lipid Mediat 96:14-20, 2011

62. Fox A, Medhurst $S$, Courade JP, et al: Antihyperalgesic activity of the cox-2 inhibitor lumiracoxib in a model of bone cancer pain in the rat. Pain 107:33-40, 2004

63. Sabino MA, Ghilardi JR, Jongen JL, et al: Simultaneous reduction in cancer pain, bone destruction, and tumor growth by selective inhibition 
of cyclooxygenase-2. Cancer Res 62:7343-7349, 2002

64. Sheng $\mathrm{H}$, Shao J, Kirkland SC, et al: Inhibition of human colon cancer cell growth by selective inhibition of cyclooxygenase-2. J Clin Invest 99: 2254-2259, 1997

65. Falk S, Uldall M, Heegaard AM: The role of purinergic receptors in cancer-induced bone pain. J Osteoporos 2012:758181, 2012

66. Kaan TK, Yip PK, Patel S, et al: Systemic blockade of $\mathrm{P} 2 \mathrm{X} 3$ and $\mathrm{P} 2 \mathrm{X} 2 / 3$ receptors attenuates bone cancer pain behaviour in rats. Brain 133:25492564, 2010

67. González-Rodriguez S, Pevida M, Roques BP, et al: Involvement of enkephalins in the inhibition of osteosarcoma-induced thermal hyperalgesia evoked by the blockade of peripheral P2X3 receptors. Neurosci Lett 465:285-289, 2009

68. Hansen RR, Nasser A, Falk $S$, et al: Chronic administration of the selective $\mathrm{P} 2 \mathrm{X} 3, \mathrm{P} 2 \mathrm{X} 2 / 3$ receptor antagonist, A-317491, transiently attenuates cancer-induced bone pain in mice. Eur J Pharmacol 688:27-34, 2012

69. Wu JX, Xu MY, Miao XR, et al: Functional up-regulation of $\mathrm{P} 2 \mathrm{X} 3$ receptors in dorsal root ganglion in a rat model of bone cancer pain. Eur $\mathrm{J}$ Pain 16:1378-1388, 2012

70. Abbadie C, Besson JM: C-fos expression in rat lumbar spinal cord during the development of adjuvant-induced arthritis. Neuroscience 48:985993, 1992

71. Wagner R, DeLeo JA, Coombs DW, et al: Spinal dynorphin immunoreactivity increases bilaterally in a neuropathic pain model. Brain Res 629:323326, 1993

72. Urch $C E$, Donovan-Rodriguez $T$, Dickenson $\mathrm{AH}$ : Alterations in dorsal horn neurones in a rat model of cancer-induced bone pain. Pain 106:347356, 2003

73. Donovan-Rodriguez $\mathrm{T}$, Dickenson $\mathrm{AH}$, Urch CE: Superficial dorsal horn neuronal responses and the emergence of behavioural hyperalgesia in a rat model of cancer-induced bone pain. Neurosci Lett 360:29-32, 2004

74. Donovan-Rodriguez T, Dickenson AH, Urch CE: Gabapentin normalizes spinal neuronal responses that correlate with behavior in a rat model of cancer-induced bone pain. Anesthesiology 102: 132-140, 2005

75. Urch CE, Donovan-Rodriguez T, Gordon-Williams $R$, et al: Efficacy of chronic morphine in a rat model of cancer-induced bone pain: Behavior and in dorsal horn pathophysiology. J Pain 6:837-845, 2005

76. D'Mello R, Dickenson AH: Spinal cord mechanisms of pain. Br J Anaesth 101:8-16, 2008

77. Gu X, Zhang J, Ma Z, et al: The role of $\mathrm{N}$-methyl-D-aspartate receptor subunit NR2B in spinal cord in cancer pain. Eur J Pain 14:496-502, 2010
78. Menéndez $L$, Lastra $A$, Hidalgo $A$, et al: Peripheral opioids act as analgesics in bone cancer pain in mice. Neuroreport 14:867-869, 2003

79. Luger NM, Sabino MA, Schwei MJ, et al: Efficacy of systemic morphine suggests a fundamental difference in the mechanisms that generate bone cancer vs inflammatory pain. Pain 99:397-406, 2002

80. Vermeirsch $\mathrm{H}$, Nuydens RM, Salmon PL, et al: Bone cancer pain model in mice: Evaluation of pain behavior, bone destruction and morphine sensitivity. Pharmacol Biochem Behav 79:243-251, 2004

81. El Mouedden M, Meert TF: The impact of the opioids fentanyl and morphine on nociception and bone destruction in a murine model of bone cancer pain. Pharmacol Biochem Behav 87:30-40, 2007

82. El Mouedden M, Meert TF: Evaluation of pain-related behavior, bone destruction and effectiveness of fentanyl, sufentanil, and morphine in a murine model of cancer pain. Pharmacol Biochem Behav 82:109-119, 2005

83. Gonçalves L, Dickenson AH: Asymmetric time-dependent activation of right central amygdala neurones in rats with peripheral neuropathy and pregabalin modulation. Eur J Neurosci 36:32043213, 2012

84. Bannister $K$, Bee LA, Dickenson AH: Preclinical and early clinical investigations related to monoaminergic pain modulation. Neurotherapeutics 6:703-712, 2009 